\title{
Global Dilemma and Contemporary Educational Reform
}

\author{
Naizhu Huang \\ Institute of Higher Education Research \\ Xiangnan University, \\ Chenzhou 423000, China \\ xnxyhnzh@163.com
}

\author{
Lijuan $\mathrm{Ye}^{*}$ \\ School of Chemical Biology and Environmental \\ Engineering \\ Xiangnan University, \\ Chenzhou 423000, China \\ yelijuan68116@163.com \\ * Corresponding Author
}

\begin{abstract}
With the rapid development of the global economy and technology, the global connections and interactions become even higher, and globalization has become a consensus. In the meantime of creating wealth, globalization also brings dilemma to human beings, and poses a threat to sustainable human development. Faced with the global dilemma, as an important subsystem in the social system, education should be vigorously reformed, abandon the traditional market-oriented educational paradigm, build the diversified alternative education model, and develop global citizens with global consciousness, democracy, fairness, and artistic appreciation.
\end{abstract}

Keywords-globalization; global dilemma; education model; education reform; alternative education

\section{GLOBALIZATION AND DILEMMA}

Now human beings are in a globalized era. With the development of information and communication technology, all kinds of ideas, goods and even rapid talents rapidly flow in the world, and the connections and interactions among people become even higher. Director of AOL Time Warner once said at the beginning of the $21^{\text {st }}$ century, "We do not want to be seen as an American company, because we think with the global mindset." What is globalization? Gilder Delandi considered that globalization referred to when people were carrying out the economic, political, social and cultural exchanges, the geographical restrictions are being gradually reduced. In other words, globalization is the changes in geographical space, more specifically, "spatial de-territorialization" [1]. Waters thought that globalization contains the objective and subjective dimensions. From an objective sense, it referred to various economic, political and cultural activities were constantly breaking the geographical restrictions; from a subjective sense, it referred to the people were constantly aware of the existence of facts, and adjusting these changes by adjusting their life [2]. The core of globalization is the change in global capital flow mode, capital and production, changes in consumption contact information, changes in energy use and consumption patterns, information and knowledge creation, changes in transfer and preservation mode, changes in labor employment and usage pattern, as well as the changes of value creation, distribution, preservation and destruction modes. Today, globalization has led profound, rapid and fundamental changes in various social aspects, changed the way of work in the world, the way people understand each other, and even the composition of the society.

There is no doubt that globalization has brought the rapid growth of the global wealth, but the globalization established on the basis of market economy and competition does not bring well-beings to all mankind; on the contrary, it reduces the human safety factor, and seriously damages human equality, sustainability and social equity value system. In particular, globalization brings five dilemmas posing serious threats to sustainable human development:

\section{A. Widened gap Between the Rich and the Poor}

The gap between the rich and the poor has been widened sharply, that is, the largest beneficiary of economic globalization is the rich population, yet most developing countries are still confronted with poverty, hunger, malnutrition and poor water quality. Since the globalization is rooted in the free market economy emphasizing competition and dominant values, despite the rapid growth of social wealth, the distribution of wealth between the rich and the poor is seriously imbalanced, and the reality of "imbalanced development" has broken the fantasy that the poor population will be the beneficiary of globalization. According to American statistics, 2.8 billion people are still living in poverty, and more than 20,000 people die every day because they are too poor to live [3]. The widened gap between the rich and the poor has brought about intensified social inequality and social unrest. 


\section{B. Environmental Disaster}

The natural environment is destroyed, and there may be serious natural disasters in the future. UN World Commission on Environment and Development, the 2002 World Summit on Sustainable Development in Johannesburg warned against the sustainable way of life, the globalization has brought an undeniable reality that the natural environment has been severely and accelerating destructed. In the face of changes in the environment, the earth's sustainable repairing, updating and rebalancing ecological capacities are seriously threatened,. If the environment continues to deteriorate, human will face an environmental disaster in the uncertain future.

\section{Urban Poor Increase}

More than half of the population are now living in an urban environment for the first time in history. The United Nations estimates a quarter of the world's population will live in urban slums by 2030. Globalization leads to mass migration movements; they will immigrate to other countries with the legitimate, illegal or refugee status, or enter the country's cities to search jobs, education, health care and other social services. The main reason is uneven economic interest distribution between the urban and rural areas, and the technological development promotes the transport to realize population mobility within a short time. The United Nations estimates a quarter of the world's population will live in urban slums by 2030. If the governments fail to take precautions in housing, drinking water, sewage, public health and safety, education and other fields, the human beings will face the large-scale outbreak of tuberculosis, cholera and other diseases, and the social phenomena that cause serious harm to the society will exacerbate, such as human trafficking, prostitution and drug trafficking.

\section{AIDS Threat}

HIV continues to multiply, whose threat to the society is more serious than its threat to the economic development. HIV reproduction is almost synchronized with the globalization process and movement of population, and becomes a major illness of the poor. Its diffusion capacity can be imagined. AIDS threat to society is more serious than its threat to economic development, which will lead to a sharp reduction in social race.

\section{E. Values and Interests Conflict}

On the one hand, the contradictions between cultures, between countries, and even civilizations began to highlight; on the other hand, globalization has led to the development of multicultural society, the world becomes smaller, and the connections between countries get increasingly closer. With the deepening of globalization, the connection between people and between countries is getting closer and more interdependent. As is known to all, the world grows smaller, exhibiting the features of "Global Village". With the large population movements, globalization enables the society to appear unprecedented internal social stratification and cultural and moral values conflict, such as there is a serious conflict between free and democratic Western social values and Islamic cultures and its social values. In the past, all countries cooperate to win the competition, and the present world coordinates the fundamental goal, values and interests, which have become the major topic. Unfortunately, in the globalization process, the world does not reach much consensus on major problems. Even if the consensus on respecting the human dignity and environmental safety, the human beings have to be at the cost of weaken values, which is contrary to the direction of our pursuit of more equal and more lasting global relations.

\section{SOLUTION TO GLOBAL DILEMMA AND CONTEMPORARY EDUCATIONAL REFORM}

In the globalization era, how to cope with the global dilemma? It is known that dilemma is different from problems, and the problems are barriers objectively existing in the pursuit of goals. When removing the barriers and disruptive factors in reality through the improvement or update means, the problems will be solved. However, dilemma is different, its interdependent development direction is at a stalemate, and it cannot be solved because of incompatibility between various values and interests in the complex interdependent relation, so solutions can only be foundto plight. For example, in the process of globalization, although the global wealth continues to grow, the number of people suffering from hunger is also rising, indicating that hunger is not caused by food shortages, but caused by unfair distribution of new wealth arising from global competition and dominant values. The reason that people cannot change the current situation is that the "cost" of people who are suffering and hungry is far less than the "price" to reconstruct a new global political pattern with new food production and distribution, so the world starvation is not a problem but a plight. In addition, the emergence of complex global interdependence has led to the accelerated transformation from problem solving to dilemma decision. In the process of solving global dilemma, what role should education play? From early childhood to graduation from college, as a social undertaking, education is the dead center of these complex processes of change. Education teaches young people the views of "how does the world work and how should it work". Education teaches the meaning of life, desire, value and wisdom to the educated. In a social environment with sharp changes, the essentially conservative education with orientation of spreading and storing knowledge will also face the challenges of new things, invention and innovation, so as to reform and choose the tension in response to the surrounding environmental changes. Currently the combination of complex interdependence, non-linear changes as well as the significant transformation from problem solving to plight decision constitute a strong recognition, that is, resolutely abandon the modernist concept of education, because such an education is a controllable activity spreading the specific, predetermined and standardized knowledge and skill entity. Instead, education needs to 
comprehensively focus on how to creatively cultivate sensitive appreciation of the arts together with the ability of undertaking the sharing construction of meaning. However, in order to realize in a sustained and effective way, it is essential to break the original interdependence between education and market economy, and abandon the practice of educational reform with market orientation, because this practice results in the blind retrogression of education and make education fall into a dull and destructive path. Currently, the world's dominant educational pattern is the educational pattern based on the curriculum and competitiveness orientation. It cannot adapt to the complex changes in the global environment, and it is difficult to cultivate global citizens with democratic and fair and consciousness and rich appreciation. Such an education is a booster of social injustice as well as the root cause for human beings to fall into universal dilemma. Therefore, the acceleration of promoting the contemporary educational reform is an effective measure to deal with global dilemma.

\section{A. Global Citizen Moral Education Concept in Multicultural Perspective}

Multiculturalism requires people to respect the cultural differences among countries, and emphasizes the diversity of culture and education. To respect for diversity, people must regard "inclusiveness" as an extremely important common philosophy in the present society. Even if people cannot accept or agree with the different cultural practices, they should at least be "inclusive", yet inclusiveness is conditional. All cultures should accept the legal status of other cultures, and make it co-exist with its own unique idea. As long as these ideas and practices conform to the moral appeal of multiculturalism itself, that is, multiculturalism should not recognize the legitimacy of all cultural ideas and practices, but instead, they should recognize the culture which is not violating the multiculturalism itself as well as the culture not violating the principle of fairness. For example, some cultures might recognize that oppression of women, while other cultures cannot recognize, because it violates the principle of universal multiculturalism which is not respecting others. Multiculturalism opposes to use any culture to press other cultures with "cultural hegemony", which considers that the universal moral code and educational concept are indeed present, whether this code and concept are originated from specific cultures and whether they are accepted by different cultures. The core moral principle of multiculturalism emphasizes to respect every individual's rights as a person as well as the principles of equality, freedom, equality of opportunity, judicial fairness and critical thinking cultivation. The global education adapting to this principle shall aim to cultivating the global citizens, educating students the rights, responsibilities and sense of loyalty of global citizens, encouraging students to question the national sovereignty principle constructed by The Peace Treaty of Westphalia, so that it loses the position in people's subjective consciousness and objective discourse system. Ian Lister pointed out in Educating Beyond the
Nation, "Global education has three main characteristics. First is to cultivate students' global vision and awareness of the interdependent world; second is to teach and learn the global issues - war and peace, development, multicultural society, human rights, environment and human future alternatives; the third is the teaching method emphasizing students' active participation, and this method is affected by John Dewey, Karl Rogers and other humanists [4]. The method is a thought with holism." Global education can meet a need, that is, rebuilding a global citizenship to accommodate the multicultural and interdependent world. The educational approach includes the cultivation of global consciousness, enhancing the global understanding of teaching and learning; adding the internationalization and globalization contents in the existing school course; establishing the school curriculum in order to promote the international and intercultural understanding; building a global citizen culture through the schools; helping young people to participate in volunteer activities at home and abroad. Global education must be based on the below three principles: the education is guided by the democratic principle and democratic process and serving the democratic principle and democratic process; education aims to build the global citizen identity; education focuses on the shared value and moral code. In the interconnected and interdependent world, education shall cultivate the global citizens with initiatives who can cope with various challenges, and the key is to cultivate students to have the following values and skills: freedom, justice, tolerance, respect for truth, respect the reasoning, analysis and reasoning skills, negotiation and reconciliation skills, which are the basis of democratic thoughts and human rights demands.

\section{B. Educational Goal with the Core of Social Equality}

American scholar Labaree said, there were three very important educational goals which were not yet competitive- to improve the democracy and equality, to promote social mobility and to improve the social efficiency. Although these three educational goals were not mutually exclusive, in a specific period, usually one of the three would dominate [5]. The social equality concept considers that education is a public good, it emphasizes equal access to education, requires to cultivate citizens with democratic consciousness, so that they have unique insights and can participate in the construction of democratic society; it emphasizes that the social culture function is instead of economic function, and it considers that the main purpose of education is to cultivate the citizens who can maximize their potentials instead of efficient workers. Of course, it does not deny the importance of vocational training, but incorporates the vocational training into the entire educational system, so that education promotes the society to develop in the direction of democracy and unity, highlights the educational function of promoting the entire social development rather than the function of individual development. Social mobility concept considers that education provides various private products to individuals, 
so that they can exchange money, power and fame in the labor market; education is competitive in essence, which plays the function of individual economic benefits and social status. Whether the individual can succeed depends on two aspects: talent and perspiration. The market mechanism always favors those gifted people who work hard; the social mobility denies the education's role in promoting social equality and economic status redistribution, and the social formation process is completely determined by market competition. In terms of social equality, it only emphasizes to strengthen the social system, in order to guarantee that everyone has access to formal schooling. Social efficiency concept considers that education is a public and private quasi-public goods, emphasizing that education should play a more important instrument role, so as to train workers who can create more wealth for the enterprise and the country; it emphasizes the operational efficiency of the education system rather than the individual needs and development, believes that the educational system shall give adequate investment in education, and train more workers with related knowledge, skills and work attitudes for the era of knowledge economy.

To adapt to the development of knowledge economy, the globalization strengthens the educational reform. Although the intensity of reform is different in various countries, the reform goals are the same, which are guided by new liberalism social image. New liberalism social image is established on the economic concept of fundamentalism proposed by George Soros. It emphasizes the economic function of educational goal, encourages to cultivate the talents who gain the maximum economic efficiency in the free competitive market, they can better apply knowledge to solve new emerging work problems in a creative manner, independently carry out works under pressure, they are featured by strong flexibility, adaptability and liquidity, have the global awareness and intercultural communication competence, and know the lifetime learning. In essence, new liberalism social image is a social efficiency concept highlighting the educational goal, and the educational reform of many countries are based on following concepts: only by adjusting the educational system can the social and economic development be realized, which enables it to meet the market demands; educational system has always been regarded as the lack of efficiency and effectiveness, and it is hard to achieve its proper functions. Education should cultivate the talents who have basic Chinese and mathematical literacy capabilities, respond flexibly to all kinds of works, have creativity, master many skills, grasp new knowledge of information and communication technologies, and work in a multicultural context. Organization for Economic Cooperation and Development also pointed out, now it is necessary to adjust the education and training policies, achieve information economy, and make contribution to promoting employment, culture, democracy and social cohesion. These educational policies should help us transit to a learning society. In a learning society, the educational opportunities are equal for all, and education is open to all. The society encourages and motivates all people to participate in learning, regardless of regular schooling or lifetime self-learning [6]. In the final analysis, the above paragraphs show that social efficiency is the ultimate value of education, whereas social equality, social mobility, social cohesion or even social cohesion are educational goals just subordinating to social efficiency. However, the educational concept based on market economy with the goal of social efficiency has led to individualism, the relationship between social cohesion, stability and trust has declined, and people cannot feel the direct connection between the increase in economic growth and happiness. No wonder Don Adams commented, "Education is the most important factor of social development as well as one of the most impractical fairy tale in the $20^{\text {th }}$ century". With the advance of globalization, the social efficiency concept will destroy the educational career, so the educational goal concept with social equality as the core and combining social efficiency with social mobility is the right path to save education, the solution to global dilemma and promoting the global harmony in the globalization process, as well as the core of the democratic educator John Dewey's educational philosophy.

\section{School Education Concept with Selective Education as the Core}

Traditional education based on competition, control and dominant market considers that education mainly cultivate the market-related capabilities of students, instead of cultivating the students' appreciation and sharing artistic appreciation. Ability is unlike appreciation, which is usually understood as a power freedom. Owning it does not guarantee that human can live a valuable life, and appreciation is freedom of power, which is not constituted by abilities that decide the desire results but by the abilities of skilled response to situation opportunity. It represents a function forming wisdom, training the control ability and clear morality. The market-oriented education designs the school into an efficiency institute in line with the factory management, students are rudely regarded as "raw materials" that the school conducts commercial processing in particular time, and finally they are manufactured to be unified "refined products". The basic features of this education is that the core of teacher-student relationship is the authoritarianism relationship; Insufficient training and low pay make the teacher teams be very unstable; generally the teaching methods do no longer benefit from cognitive psychology and student development; teachers generally do not like discussion and question but prefer repeating what books say; the main role of schooling is to select qualified students for the next level of education; select talents through competitive examination system; this system requires the repeated rote learning rather than critical thinking; the main activities of the formal school system is to train students to pass these exams; students and parents are more concerned about the certificates rather than the learning contents [7]. Today the world's major national educational reform with the US as 
the representative is to strengthen the standardization, performance, evaluation, and learning outcomes. In essence, it adopts the industrial management feature, and incorporates individual development into the control, competitive and obedient system. In the 1970s, Ivan Illich severely criticized the regular schools and its representative meanings in Deschooling Society, after being educated, students could not distinguish teaching from learning, updating from education, graduate diploma from aptitude, together with proficiency in mastering knowledge from proposing new insights, his imagination was domesticated to be only receiving service rather than values. Medical care was mistaken for health care, social welfare was mistaken for the improvement of social life, police protection was mistaken for security, military stability was mistaken for national security, fierce competition was mistaken for efficient work, not just education, social reality was also domesticated [8]. He suggested replacing education network with educational funnel and learning network with regular schools. Although his criticism hit the weakness of school education at that time, it quietly exits the stage of history because of incompatibility with the times.

At present, the globalization trend is irreversible, global dilemma has been a serious threat to the sustainable human development, prosperity and harmony. As an important subsystem of social system, education must be reformed fundamentally if it has to play a vital role in solving the global dilemma. In other words, it transforms the course method of complete obedience to control, competition, selection and other value concept construction into a diverse educational quality. This educational quality can produce stable and responsible commitment, coordination and beneficial appreciation. People must abandon the course model connecting learning with "getting it" or occupation of knowledge, but instead, regard learning as an undergoing improvisation with situation meaning as well as the enriching mature relationship between things. This understanding opposes modernist's splitting between soul/intellectual and body/emotion, affirms that learning is always the practical set of man and society, that is, the learning activity is understood to be a human activity that can think as well as the connection of qualitative changes in the relationship between society and nature. Alternative education is the concentrated expression of the above reform thoughts, its main features are: Children's center rather than teacher-driven pedagogy; active rather than passive learning; the classes of diverse grades with consecutive course learning; contribution of full-time training teachers, part-time training teachers; families and other community members' participation in a wide range of children's learning and school management; partnership guidance elder and (or) fast-learning children help young children and (or) slow-learning children; seriously development of self-study materials, those children alone or in small groups can learn by themselves, follow their own pace, and get helps from other students or teachers when necessary - Children should be responsible for their own learning; teachers and students gather the learning materials together; apply radio and other multimedia learning materials, and use TV in some cases or use computer in a few cases; ongoing or regular teacher in-service training of teachers and partner teacher counseling; ongoing guidance/evaluation/feedback system, and allowing the self-practice of this system can be modified and supplemented in methodology; free activities for children and parents between schools and communities; community participation mainly includes concerning about the nutrition, health and learning of children before receiving formal education; the local governments can adjust the school time and learning years according to real needs; the school concerns more about learning rather than teaching.

\section{ACKNOWLEDGMENT}

This study is supported by the construct program of the key discipline in human province, Hunan Provincial education science "the $12^{\text {th }} \quad$ Five-year Plan" program(XJK014BGD076), China.

\section{REFERENCES}

[1] Deland, Gerard. "Citizenship in a Global age: Society, Culture, Politics," Buckingham: Open University Press, 2000.

[2] Waters, M. “Globalization,”. London: Routledge,1995.

[3] Peter $\cdot \mathrm{D} \cdot H e r S h o c k$, transtated by RenYouqun. " Education of Innovator," Shanghai: East China Normal University Press, 2009,pp27.

[4] Lister, Ian. "Educating Beyond the Nation, in Lo, Leslie Nai-Kwai \& Man, Si-wai (eds.), Research and Endeavours in Moral and Civil Education.”. Hong Kong: Hong Kong Institute of Educational Research, 1996,pp.89

[5] Labaree, D. "How to Succeed in School without really learning: The Credential race in American education". New Haven: Yale University Press. 2003.

[6] OECD. "Globalization and Linkages to 2030: Challenges and Opportunities for OECD Countries”. Paris: OECD, 1996.

[7] Tuqan, M. I. "Education, Society and Development in Underdeveloped Countries”. Den Haag: CESO,1975.

[8] Illich, I. "Deschooling Society". New York: Harper and Row, 1970.

[9 Edgar Morin, translated by Chen YiZhuang. "Complexity theory and education”. Beijing : Peking University Press,2004,pp43.

[10] Yang Zhongkai, Liu Yongzhen. "From simplicity to complexity". System dialectics report,2002,pp47. 